\title{
GENETIC ANALYSIS OF PRE-WEANING GROWTH TRAITS OF BARKI AND RAHMANI LAMBS
}

\author{
M.H. Hammoud and M.M.I. Salem
}

Department of Animal and Fish Production, Faculty of Agriculture, Alexandria University, PC: 21545, Alexandria, Egypt

Received:30/4/2019 Accepted:20/6/2019

SUMMARY

Data relevant to 704 Barki and 732 Rahmani lambs born at Alexandria University Experimental Station between 1991-2014 were utilized in this investigation to estimate genetic parameters, breeding values and genetic trends of birth weight $(B W)$, weaning weight $(W W)$ and average daily gain $(A D G)$. The fixed effects of season and year of birth, sex of lamb, type of birth and parity on the considered traits were also studied.

The least squares analysis with unequal subclass numbers showed that the overall means of $B W, W W$ and ADG of Barki lambs were $3.69 \mathrm{~kg}, 20.53 \mathrm{~kg}$ and $139.7 \mathrm{~g}$, respectively, the corresponding values for Rahmani lambs were $3.54 \mathrm{~kg}, 20.09 \mathrm{~kg}$ and $137.8 \mathrm{~g}$, respectively. The analysis also indicated that fixed factors effects on all studied traits of both breeds were generally significant $(P<0.01$ or $P<0.05)$ except for the effects of year of birth on $B W$ and parity on $W W$ and $A D G$ of Barki lambs were not significant.

Genetic parameters and breeding values for the studied traits were estimated using the Wombat programme fitting Multiveriate Animal Models. Estimates of the direct heritability $\left(h^{2}{ }_{a}\right)$ were 0.186, 0.078 and 0.073 for $\mathrm{BW}$, $W W$ and $A D G$ of Barki lambs, respectively. The corresponding values for Rahmani lambs were 0.285, 0.130 and 0.121 , respectively. Estimates of the maternal heritability $\left(h_{m}^{2}\right)$ were $0.121,0.099$ and 0.103 for $B W, W W$ and ADG of Barki lambs, respectively. The respective values for Rahmani lambs were 0.097, 0.040 and 0.033, respectively. Estimates of the fraction of variance due to maternal permanent environmental effects $\left(C^{2}\right)$ were $0.024,0.022$ and 0.016 for $B W, W W$ and $A D G$ of Barki lambs, respectively. The corresponding values for Rahmani lambs were 0.094, 0.039 and 0.033, respectively. Maternal effects were considerable portion of variation for early growth traits of both breeds.

All correlations were positive and significant $(P<0.01)$. The genetic corrletions were extermely high, being 0.993, 0.991 and 1.000 between $B W$ and $W W$, between $B W$ and $A D G$ and between $W W$ and ADG of Barki lambs, respectively. The corresponding values for Rahmani lambs were 0.685, 0.677 and 1.000. The maternal genetic correlations were high to extremely high being of $0.775,0.753$ and 0.999 between $B W$ and $W W$, between $B W$ and $A D G$ and between $W W$ and $A D G$ of Barki lambs, respectively. The respective values for Rahmani lambs were 0.984, 0.988 and 1.000, respectively. The maternal permanent environmental correlations among growth traits of both breeds were extremely high ranged from 0.926 to 0.997. The phenotypic correlations were moderate since they varied from 0.395 to 0.479 between $B W$ and each of $W W$ and $A D G$ of both breeds, and were extremely high being 0.994 and 0.996 between $W W$ and ADG of Barki and Rahmani lambs, respectively. High and positive genetic correlations among lamb's growth traits of both breeds showed that improvement of one trait by selection would cause positive progress in the others.

The breeding values for $B W, W W$ and $A D G$ of Barki rams ranged between -0.227 and $0.333 \mathrm{~kg}$, between -1.666 and $2.444 \mathrm{~kg}$ and between -11.60 and $17.00 \mathrm{~g}$, respectively. The corresponding values for Rahmani rams were between -0.475 and $0.241 \mathrm{~kg}$, between -3.995 and $2.983 \mathrm{~kg}$ and between -27.21 and $20.57 \mathrm{~g}$. The genetic trends estimated by the regression of rams breeding values on time were positive but not significant for all traits of both breeds except for $B W$ of Rahmani lambs which was significant $(P<0.05)$. The results in general showed the need for designing an effective selection programme to improve growth traits of lambs of both breeds.

\section{Keywords: Pre-weaning growth, genetic parameters, breeding values, genetic trends, Barki, Rahmani, lambs}

\section{INTRODUCTION}

Lambs are the most profitable outcome of any sheep flock in Egypt. Early growth traits of lamb are of particular interest for the profitability in any sheep producing enterprise (Selvaggi et al. 2011, Javed et al. 2013, Mohammadi et al. 2013, Mokhatri et al. 2013, Rashidi 2013, , Jannune et al. 2015, AL-Bial et al. 2016 and Eteqadi et al. 2016). Growth traits of lambs are quantitative in nature and are influenced by lamb's genetic potential for growth, maternal genetic and permanent environmental effects and temporary environmental effects (Mostafa et al. 2011, Rashidi 2013, Mohammadi et al. 2013, Akthar et al. 2014, Jalil-Sarghale et al. 2014, Mohammadi et al. 2015, Aguiree et al. 2016, Aksoy et al. 2016, Bayeriyar and Hadi 2016, Eteqadi et al. 2016 and Taghi et al. 2016).

Knowledge of genetic and phenotypic parameters is important for determination of the optimal breeding strategies for the genetic improvement of the lambs' growth traits (Selvaggi et al. 2011, Jafari et 
al. 2012, Shokrollahi and Zandieh 2012, Javed et al. 2013, Mohammadi et al. 2013, Mokhatri et al. 2013, Rashidi 2013, Jalil-Sarghale et al. 2014, Al-Samarai et al. 2015, Aguirre et al. 2016, AL-Bial et al. 2016, Bayeriyar and Hadi 2016and Jawasreh et al. 2018). An accurate prediction of breeding value of growth traits of lambs is an integral part of most genetic improvement breeding programmes (Javed et al. 2013, Akthar et al. 2014, Roshanfekr 2014, Ahmadpanah et al. 2016, Eteqadi et al. 2016, Baneh and Ahmadpanah 2018, Yadavet al. 2018 and Sallam et al. 2019). Genetic trends for early growth traits of lambs of different sheep breeds have been indicated by several investigations (Mostafa et al. 2011, Hossein-Zadeh 2012, Javed et al. 2013, Roshanfekr 2014, Aguirre et al. 2016, Ahmadpanah et al. 2016, Eteqadi et al. 2016, Mallick et al. 2016, Baneh and Ahmadpanah 2018, Jawasreh et al. 2018, Yadav et al. 2018 and Sallam et al. 2019).
The objective of this investigation was to estimate genetic parameters, breeding values and genetic trends of birth and weaning weights and pre-weaning average daily gain of Barki and Rahmani lambs in an experimental flock of sheep.

\section{MATERIALS AND METHODS}

Data:

Data used in this investigation were from the records of the sheep flock of the Experimental Station, Faculty of Agriculture, Alexandria University. The records covered the period from 1991 to 2014 and were relevant to 704 and 732 Barki and Rahmani lambs presenting 20 and 21 rams and 205 and 214 ewes, respectively. Basic statistics and distribution of the data are show in Table 1.

Table 1: Basic statistics and distribution of the data for the studied traits of Barki and Rahmani lambs.

\begin{tabular}{lcccccc}
\hline \multicolumn{1}{c}{ Items } & \multicolumn{3}{c}{ Barki } & \multicolumn{3}{c}{ Rahmani } \\
\cline { 2 - 7 } & BW & WW & ADG & BW & WW & ADG \\
\hline Mean , (kg or g) & $3.69^{\mathrm{a}}$ & $20.53^{\mathrm{a}}$ & $139.7^{\mathrm{a}}$ & $3.54^{\mathrm{b}}$ & $20.09^{\mathrm{a}}$ & $137.8^{\mathrm{a}}$ \\
SD, (kg) & 0.60 & 4.64 & 37.00 & 0.59 & 4.27 & 33.82 \\
C.V (\%) & 16.28 & 22.95 & 26.62 & 16.76 & 22.00 & 25.23 \\
No. of records & 704 & 636 & 636 & 732 & 629 & 629 \\
No. of sires & 20 & 20 & 20 & 21 & 21 & 21 \\
No. of dams & 205 & 197 & 197 & 214 & 195 & 195 \\
No. of ram lambs & 363 & 331 & 331 & 358 & 304 & 304 \\
No. of ewe lambs & 341 & 305 & 305 & 374 & 325 & 325 \\
No. single lambs & 633 & 570 & 570 & 478 & 416 & 416 \\
No. twin lambs & 71 & 66 & 66 & 254 & 213 & 213 \\
\hline
\end{tabular}

BW: birth weight, WW: weaning weight, ADG: average daily gain.

Means of each trait with the same letter are not significantly different $(\mathrm{P}>0.05)$.

Animals were housed in semi closed pens, fed on Berseem (Trifolium alexandrinum) during winter and spring and on stubble and Berseem hay and/ or fodder sorghum (Sorghum bicolor) during summer and autumn. Supplementary concentrate ration of about $0.25 \mathrm{~kg} /$ head was offered daily along the year.

The flock was managed for all year round lambing. Females were first mated at about 18 months of age. Rams and ewes were selected as yearlings based on visual appraisal for type and size rather than on a preset intensive selection programme. Once the ewe entered the breeding flock, there is no chance for culling until the end of its productive life.

\section{Statistical procedures:}

Least squares of GLM procedure (SAS 2008) were utilize to test the significance of the fixed effects of season of birth (4 seasons), year of birth (8 periods), sex (male and female), type of birth (single and twin) and parity (8 parities) on birth weight (BW), weaning weight (WW) and average daily gain (ADG) from birth to weaning of lambs. Months of birth were classified by season into autumn births between September and November, winter births between December and February, spring births between March and May and summer births between June and August. Years of birth from 1991-2014 were classified to eight periods $(1=1991-1993,2=1994-1996$,
$3=1997-1999,4=2000-2002,5=2003-2005,6=$ 2006-2008, 7= 2009-2011 and 8=2012-2014). Parity was between 1 and 7 or over. Each breed data were analyzed separately. The statistical model fitted was:

$\mathbf{Y}_{\mathrm{ijklmn}}=\boldsymbol{\mu}+\mathbf{A}_{\mathbf{i}}+\mathbf{B}_{\mathbf{j}}+\mathbf{C}_{\mathbf{k}}+\mathbf{D}_{\mathbf{l}}+\mathbf{P}_{\mathbf{m}}+\mathbf{e}_{\mathbf{i j k l m n}}$ where,

$\mathbf{Y}_{\mathbf{i j k l m n}}$ : either $\mathrm{BW}, \mathrm{WW}$ or $\mathrm{ADG} ; \boldsymbol{\mu}$ : an underlying constant specific to each trait; $\mathrm{A}_{\mathrm{i}}$ : the fixed effect of $i^{\text {th }}$ season of birth(i=1,2,3 and 4); $\mathbf{B}_{\mathbf{j}}$ : the fixed effect of $j^{\text {th }}$ year of birth $(j=1,2,3 \ldots \ldots 8) ; \mathbf{C}_{\mathbf{k}}$ : the fixed effect of $\mathrm{k}^{\text {th }} \operatorname{sex}(\mathrm{k}=1$ and 2$) ; \mathbf{D}_{\mathbf{l}}$ : the fixed effect of $1^{\text {th }}$ type of birth $(\mathrm{l}=1$ and 2$) ; \mathrm{P}_{\mathrm{m}}$ : the fixed effect of $\mathrm{m}^{\text {th }}$ parity $(\mathrm{m}=1,2,37)$ and $\mathbf{e}_{\mathrm{ijklmn}}$ : random residual assumed to be independent normally distributed with mean zero and variance $\sigma_{e}^{2}$.

Variance components, genetic parameters and breeding values were estimated using the Wombat programme (Meyer 2006) fitting multivariate animal model. The assumed model was:

$$
\mathrm{y}=\mathrm{Xb}+\mathrm{Z}_{\mathrm{a}} \mathrm{a}+\mathrm{Z}_{\mathrm{m}} \mathrm{m}+\mathrm{Z}_{\mathrm{c}} \mathrm{c}+\mathrm{e}
$$

where $\mathrm{y}$ is a $\mathrm{n} \times 1$ vector of observations for each trait; b, a, m, c and e are vectors of fixed effects (season of birth, year of birth, sex and type of birth and parity), direct additive genetic effects, maternal additive genetic effects, maternal permanent environmental effects and the residual effects, respectively; $\mathrm{X}, \mathrm{Za}, \mathrm{Zm}, \mathrm{Zc}$ are the incidence 
matrices of fixed effects, direct additive genetic effects, maternal genetic effects and maternal permanent environmental effects; $\mathrm{A}$ is the numerator relationship matrix between animals; and $\sigma_{\mathrm{am}}$ is the covariance between additive direct and maternal genetic effects. The (co)variance structure for the model was:

$\mathrm{V}(\mathrm{a})=\mathrm{A} \sigma_{\mathrm{a}}^{2}, \mathrm{~V}(\mathrm{~m})=\mathrm{A} \sigma_{\mathrm{m}}^{2}, \mathrm{~V}(\mathrm{c})=\mathrm{I}_{\mathrm{P}} \sigma_{\mathrm{c}}^{2}, \mathrm{~V}(\mathrm{e})=$ $I_{R} \sigma_{e}^{2}$ and $\operatorname{Cov}(a, m)=0$

where $I_{P}$ and $I_{R}$ are identity matrices with orders equal to the number of dams and the number of lambs, respectively and $\sigma_{\mathrm{a}}^{2}, \sigma_{\mathrm{m}}^{2}, \sigma_{\mathrm{c}}^{2}$, and $\sigma_{\mathrm{e}}^{2}$ are direct additive genetic variance, maternal additive genetic variance, maternal permanent environmental variance, and residual variance, respectively. Estimates of heritability $\left(\mathrm{h}_{\mathrm{a}}^{2}\right)$, maternal heritability $\left(\mathrm{h}_{\mathrm{m}}^{2}\right)$ and permanent maternal environmental effects $\left(c^{2}\right)$ were calculated as ratios of estimates of $\sigma_{a}^{2}, \sigma_{m}^{2}$, and $\sigma_{c}^{2}$, respectively, to the phenotypic variance $\left(\sigma_{\mathrm{p}}^{2}\right)$.

The genetic trends for the studied traits were computed as the regression coefficients of rams breeding values on their year of birth.

\section{RESULTS AND DISCUSSION}

The current means of BW, WW and ADG of Barki lambs were $3.69 \mathrm{~kg}, 20.53 \mathrm{~kg}$ and $139.7 \mathrm{~g}$, respectively. The corresponding values for Rahmani lambs were $3.54 \mathrm{~kg}, 20.09 \mathrm{~kg}$ and $137.8 \mathrm{~g}$, respectively, (Table 1). The present means were higher than those $(3.56 \mathrm{~kg}, 19.29 \mathrm{~kg}$ and $131.02 \mathrm{~g}$, respectively) of $\mathrm{BW}, \mathrm{WW}$ and $\mathrm{ADG}$ of Barki lambs depicted by Gad and El-Wakil (2013), and those $(3.42 \mathrm{~kg}, 19.49 \mathrm{~kg}$ and $135.00 \mathrm{~g}$, respectively) of Rahmani lambs depicted by Abbas et al. (2010) on other experimental flocks of sheep in Egypt.

\section{Fixed effects:}

Table 2 shows the results of analysis of variance for fixed effects on all studied traits. The fixed effects on all studied traits of both breeds were generally significant $(\mathrm{P}<0.01$ or $\mathrm{P}<0.05)$ except for the effects of year of birth on BW and parity on WW and ADG of Barki lambs that were insignificant. Similar significant fixed effects on BW, WW and ADG of lambs of various sheep breeds have been well depicted in the literature (Selvaggi et al. 2011, Jafari et al. 2012, Mohammadi et al. 2013, Mokhatri et al. 2013, JalilSarghale et al. 2014, Rahimi et al. 2014, Al-Samarai et al. 2015, Aguiree et al. 2016, AL-Bial et al. 2016, Taghi et al., 2016, Tohidi et al.2016, Marufa et al., 2017 and Jawasreh et al., 2018).

Table 2: Mean squares (MS) and level of significance $((\mathrm{P}<)$ for factors affecting studied traits of Barki and Rahmani lambs.

\begin{tabular}{|c|c|c|c|c|c|c|c|c|c|}
\hline \multirow{2}{*}{$\begin{array}{l}\text { Source of } \\
\text { variation }\end{array}$} & \multicolumn{5}{|c|}{ Barki } & \multicolumn{4}{|c|}{ Rahmani } \\
\hline & df* $^{*}$ & $\begin{array}{l}\text { MS } \\
(\mathbf{P}<)\end{array}$ & BW & WW & ADG & $\begin{array}{l}\text { MS } \\
(\mathbf{P}<)\end{array}$ & BW & WW & ADG \\
\hline \multirow{2}{*}{$\begin{array}{l}\text { Season of } \\
\text { birth }\end{array}$} & 3 & MS & 1.1052 & 218.3 & 15187.5 & MS & 1.7497 & 87.13 & 6342.7 \\
\hline & & $(\mathrm{P}<)$ & 0.0278 & 0.0001 & 0.0001 & $(\mathrm{P}<)$ & 0.0020 & 0.0041 & 0.0014 \\
\hline \multirow{2}{*}{$\begin{array}{l}\text { Year of } \\
\text { birth }\end{array}$} & 7 & MS & 0.6526 & 339.2 & 24252.3 & MS & 1.5113 & 375.3 & 26487.2 \\
\hline & & $(\mathrm{P}<)$ & 0.0836 & 0.0001 & 0.0001 & $(\mathrm{P}<)$ & 0.0001 & 0.0001 & 0.0001 \\
\hline \multirow{2}{*}{$\begin{array}{l}\text { Sex of } \\
\text { lamb }\end{array}$} & 1 & $\mathrm{MS}$ & 8.4796 & 556.6 & 29685.2 & MS & 4.9514 & 225.5 & 12981.4 \\
\hline & & $(\mathrm{P}<)$ & 0.0001 & 0.0001 & 0.0001 & $(\mathrm{P}<)$ & 0.0002 & 0.0007 & 0.0011 \\
\hline \multirow{2}{*}{$\begin{array}{l}\text { Type of } \\
\text { birth }\end{array}$} & 1 & MS & 50.072 & 1421.7 & 64205.6 & MS & 57.699 & 1114.2 & 51403.7 \\
\hline & & $(\mathrm{P}<)$ & 0.0001 & 0.0001 & 0.0001 & $(\mathrm{P}<)$ & 0.0001 & 0.0001 & 0.0001 \\
\hline \multirow[t]{2}{*}{ Parity } & 6 & MS & 4.4481 & 44.71 & 1996.5 & MS & 4.4875 & 55.61 & 2690.7 \\
\hline & & $(\mathrm{P}<)$ & 0.0001 & 0.0620 & 0.1946 & $(\mathrm{P}<)$ & 0.0001 & 0.0097 & 0.0392 \\
\hline \multirow[t]{2}{*}{ Error } & & MS & 0.3616 & 22.21 & 1380.6 & MS & 0.3514 & 19.54 & 1208.9 \\
\hline & & & $(685)$ & $(617)$ & $(617)$ & & $(713)$ & $(610)$ & $(610)$ \\
\hline
\end{tabular}

BW: birth weight, WW: weaning weight, ADG: average daily gain.

Not significant $(\mathrm{P}>0.05)$; Significant $(\mathrm{P}<0.05)$

Figures within parentheses are the degrees of freedom (df) of the error term.

\section{Genetic and phenotypic parameters:}

\section{Variance components and heritabilities:}

Estimates of all components of variance $\left(\sigma_{\mathrm{a}}^{2}, \sigma_{\mathrm{m}}^{2}\right.$, $\sigma_{c}^{2}, \sigma_{e}^{2}$ and $\left.\sigma_{p}^{2}\right)$, direct and maternal heritabilities $\left(h^{2}\right.$, and $\mathrm{h}_{\mathrm{m}}^{2}$ ) and fraction of variance due to maternal permanent environmental effects $\left(\mathrm{c}^{2}\right)$ for $\mathrm{BW}, \mathrm{WW}$ and ADG of Barki and Rahmani lambs are found in Table 3. Estimates of $\sigma^{2}$ and $h^{2}$ for all studied traits were higher for Rahmani than Barki lambs. An adverse trend was observed for $\sigma_{m}^{2}$ and $h^{2}$ for all traits. The estimates of $h_{a}^{2}$ were higher than $h^{2}$ for BW of both breeds. The estimates of $h^{2}$ were relatively lower than $\mathrm{h}_{\mathrm{m}}^{2}$ for $\mathrm{WW}$ and $\mathrm{ADG}$ in Barki lambs. Whereas, the estimates of $\mathrm{h}^{2}{ }_{\mathrm{a}}$ were higher than $\mathrm{h}_{\mathrm{m}}^{2}$ for $\mathrm{WW}$ and $\mathrm{ADG}$ in Rahmani lambs. The estimates of $\sigma_{c}^{2}$ and $c^{2}$ were higher for Rahmani than Barki lambs for all traits. Estimate of $\sigma_{e}^{2}$ of BW was slightly higher for Barki than Rahmani lambs. An opposite trend was observed for WW and ADG. Estimates of $\sigma_{p}^{2}$ for BW were equal for both breeds and for WW and ADG were higher for Rahmani than Barki lambs. 
Table 3. Variance components and heritabilities for the studied traits of Barki and Rahmani lambs

\begin{tabular}{|c|c|c|c|c|c|c|}
\hline \multirow{2}{*}{ Item } & \multicolumn{3}{|c|}{ Barki } & \multicolumn{3}{|c|}{ Rahmani } \\
\hline & BW & WW & ADG & BW & WW & ADG \\
\hline$\sigma_{a}^{2}$ & 0.078 & 4.30 & 208.26 & 0.118 & 8.07 & 378.17 \\
\hline$\sigma_{m}^{2}$ & 0.050 & 5.52 & 294.17 & 0.040 & 2.50 & 102.58 \\
\hline$\sigma_{c}^{2}$ & 0.010 & 1.23 & 46.23 & 0.039 & 2.39 & 104.38 \\
\hline$\sigma_{e}^{2}$ & 0.281 & 44.46 & 2301.58 & 0.217 & 49.11 & 2536.71 \\
\hline$\sigma_{p}^{2}$ & 0.421 & 55.52 & 2850.26 & 0.414 & 62.08 & 3121.85 \\
\hline$h^{2}{ }^{2} \pm S E$ & $0.186(0.115)$ & $0.078(0.096)$ & $0.073(0.092)$ & $0.285(0.140)$ & $0.130(0.086)$ & $0.121(0.083)$ \\
\hline $\mathbf{h}^{2}{ }_{\mathrm{m}} \pm \mathrm{SE}$ & $0.121(0.085)$ & $0.099(0.070)$ & $0.103(0.069)$ & $0.097(0.092)$ & $0.040(0.072)$ & $0.033(0.069)$ \\
\hline$c^{2} \pm S E$ & $0.024(0.061)$ & $0.022(0.059)$ & $0.016(0.058)$ & $0.094(0.067)$ & $0.039(0.059)$ & $0.033(0.056)$ \\
\hline
\end{tabular}

BW: birth weight, WW: weaning weight, ADG: average daily gain.

$\boldsymbol{\sigma}_{\mathbf{c}}{ }_{\mathrm{c}}$ : maternal permanent environmental variance, $\mathrm{c}^{2}$ : portion of maternal permanent environmental effects.

The current estimates of $\mathrm{h}^{2}$ a were $0.186,0.078$ and 0.073 for BW, WW and ADG of Barki lambs, respectively. The corresponding values for Rahmani lambs were $0.285,0.130$ and 0.121 (Table 3 ). The current low to moderate $\mathrm{h}_{\mathrm{a}}^{2}$ values could be attributed to the low level of nutrition and the differences in managing practices at the sheep experimental station, causing large environmental variations. Jalil-Sarghale et al. (2014) reported low $\mathrm{h}^{2}{ }_{\mathrm{a}}$ estimates of $0.06,0.12$ and 0.08 for BW, WW and ADG of Baluchi sheep, respectively in Iran. Also, low $\mathrm{h}^{2}$ a estimates of 0.124 and 0.169 for $\mathrm{BW}$ and $\mathrm{WW}$ of Zandi sheep, respectively in Iran were indicated by Taghi et al. (2016). Moderate $\mathrm{h}^{2}$ a estimates of $0.22,0.20$ and 0.38 for BW, WW and ADG of Santa Ines sheep, respectively In Brazil were depicted by Aguiree et al. (2016). Moderate to high $h^{2}$ a estimates of $0.19,0.43$ and 0.30 for $\mathrm{BW}, \mathrm{WW}$ and $\mathrm{ADG}$, respectively of White Boni sheep, respectively in Yemen were found by AL-Bial et al. (2016). Moderate to high $\mathrm{h}_{\mathrm{a}}^{2}$ estimates from six models ranged from 0.24 to 0.44 for BW and from 0.27 to 0.40 for WW of Karayaka lambs in Turkey were also depicted by Aksoy et al. (2016). In India, Mallick et al. (2017) documented $h^{2}$ estimates of 0.29 and 0.16 for BW and WW of Bharat Merino sheep, respectively. In Iran, Baneh and Ahmadpanah (2018) reported moderate $\mathrm{h}^{2}$ a estimates of 0.285 and 0.371 for $\mathrm{BW}$ and WW of Ghezel sheep, respectively. Jawasreh et al. (2018) obtained $\mathrm{h}^{2}{ }_{\mathrm{a}}$ estimates of $0.30,0.19$ and 0.19 for BW, WW and ADG of Awassi sheep, respectively in Jordan. Sallam et al. (2019) depicted low $\mathrm{h}^{2}{ }_{\mathrm{a}}$ estimates of $0.07,0.15$ and 0.16 for BW, WW and ADG of Barki lambs, respectively in another experimental flock in Egypt. The low $\mathrm{h}^{2}{ }_{\mathrm{a}}$ estimates for growth traits of both breeds except for BW of Rahmani lambs indicate that direct genetic effects represent a little portion of the variances in these traits. Hence, slow genetic progress would be obtained by direct selection for these traits.

The present estimates of $\mathrm{h}_{\mathrm{m}}^{2}$ were $0.121,0.099$ and 0.103 for $\mathrm{BW}, \mathrm{WW}$ and $\mathrm{ADG}$ of Barki lambs, respectively. The corresponding values for Rahmani lambs were $0.097,0.040$ and 0.033 (Table 3). The estimates of $h^{2}$ for all studied traits were higher for Barki than Rahmani lambs. Maternal additive effects constitute a considerable part of variation for BW of both breeds and for WW and ADG of Barki lambs only. Similarly, low $\mathrm{h}^{2}$ estimates of $0.09,0.04$ and 0.03 for BW, WW and ADG of Baluchi sheep, respectively were reported by Jalil-Sarghale et al. (2014). Aguiree et al. (2016) also depicted low $\mathrm{h}_{\mathrm{m}}^{2}$ estimates of $0.14,0.13$ and 0.10 for $\mathrm{BW}, \mathrm{WW}$ and ADG of Santa Ines sheep, respectively. Aksoy et al. (2016) obtained $\mathrm{h}_{\mathrm{m}}^{2}$ estimates ranged from 0.15 to 0.22 for BW and from 0.04 to 0.14 for WW of Karayaka lambs, respectively. Low $\mathrm{h}_{\mathrm{m}}^{2}$ estimates of 0.121 and 0.071 for BW and WW of Zandi sheep, respectively were reported by Taghi et al. (2016). Baneh and Ahmadpanah (2018) found low $\mathrm{h}_{\mathrm{m}}^{2}$ estimates of 0.113 and 0.031 for $\mathrm{BW}$ and $\mathrm{WW}$ of Ghezel sheep, respectively. Sallam et al. (2019) depicted low $\mathrm{h}_{\mathrm{m}}^{2}$ estimates of 0.06, 0.06 and 0.10 for $\mathrm{BW}, \mathrm{WW}$ and $\mathrm{ADG}$ of Barki lambs, respectively. The $\mathrm{h}_{\mathrm{m}}^{2}$ estimates obtained in this study for body weights of both breeds decreased with advanced in ages. This trend has also been reported in other studies on various sheep breeds (Jalil-Sarghale et al. 2014, Mohammadi et al., 2015, Taghi et al., 2016 and Baneh and Ahmadpanah 2018).

Estimates of the portion of variation due to maternal permanent environmental effects $\left(c^{2}\right)$ were $0.024,0.022$ and 0.016 for $\mathrm{BW}, \mathrm{WW}$ and $\mathrm{ADG}$ of Barki lambs, respectively. The respective values for Rahmani lambs were 0.094, 0.039 and 0.033 (Table 3 ). Estimates of $\mathrm{c}^{2}$ were very low for all studied traits of both breeds except that for BW of Rahmani lambs which was considerable (0.094). Differences in estimates of $\mathrm{c}^{2}$ for BW of lambs of both breeds could be attributed to uterine capacity as well as, multiple births. Similarly, Jalil-Sarghale et al. (2014) reported low $\mathrm{c}^{2}$ values of $0.09,0.08$ and 0.07 for $\mathrm{BW}, \mathrm{WW}$ and ADG of Baluchi sheep, respectively. Also, Aksoy et al. (2016) obtained $\mathrm{c}^{2}$ ranging from 0.010 to 0.098 for BW and from 0.060 to 0.093 for WW of Karayaka lambs. Moreover, Sallam et al. (2019) depicted low $c^{2}$ estimates of $0.09,0.06$ and 0.06 for $\mathrm{BW}, \mathrm{WW}$ and ADG of Barki lambs, respectively. Contradictory, Aguiree et al. (2016) reported high $\mathrm{c}^{2}$ estimates of $0.57,0.60$ and 0.48 for $\mathrm{BW}, \mathrm{WW}$ and ADG of Santa Ines sheep, respectively. 
Both maternal effects $\left(\mathrm{h}_{\mathrm{m}}^{2}\right.$ and $\left.\mathrm{c}^{2}\right)$ were 0.145 , 0.121 and 0.119 of variations in BW, WW and ADG of Barki lambs. The respective values for Rahmani lambs were 0.191, 0.079 and 0.066 (Table 3). Similarly, several studies on sheep showed that maternal effects represent a crucial portion of variation in early growth traits of lambs (Mostafa et al. 2011, Moktari et al. 2013, Rashidi 2013, Mohammadi et al. 2013, Akthar et al. 2014, Jannoune et al. 2015, Aguiree et al. 2016, Taghi et al., 2016,
Baneh and Ahmadpanah 2018, Sallam et al. 2019). Therefore, the maternal effects should be considered in the analytical model to achieve more accurate genetic evaluation for early growth traits of lambs.

\section{Genetic and phenotypic correlations:}

Table (4) shows that all correlations $\left(r_{g}, r_{m}, r_{c}\right.$ and $r_{p}$ ) among growth traits of Barki and and Rahmani lambs were positive and significant $(\mathrm{P}<0.01)$.

Table 4: Correlation coefficients among the studied traitsof Barki and Rahmani lambs.

\begin{tabular}{|c|c|c|c|c|c|c|}
\hline \multirow[b]{2}{*}{ Item } & \multicolumn{3}{|c|}{ Barki } & \multicolumn{3}{|c|}{ Rahmani } \\
\hline & BW\&WW & BW\&ADG & WW\&ADG & BW\&WW & $\begin{array}{c}\text { BW\& } \\
\text { ADG }\end{array}$ & WW\&ADG \\
\hline $\mathbf{r}_{\mathrm{g}} \pm \mathrm{SE}$ & $\begin{array}{c}0.993 * * \\
(0.318)\end{array}$ & $\begin{array}{l}0.991 * * \\
(0.351)\end{array}$ & $\begin{array}{l}1.000 * * \\
(0.007)\end{array}$ & $\begin{array}{c}0.685 * * \\
(0.276)\end{array}$ & $\begin{array}{l}0.677 * * \\
(0.298)\end{array}$ & $\begin{array}{l}1.000 * * \\
(0.003)\end{array}$ \\
\hline $\mathbf{r}_{\mathbf{m}} \pm \mathbf{S E}$ & $\begin{array}{c}0.775 * * \\
(0.239)\end{array}$ & $\begin{array}{c}0.753 * * \\
(0.257)\end{array}$ & $\begin{array}{c}0.999 * * \\
(0.004)\end{array}$ & $\begin{array}{c}0.984 * * \\
(0.543)\end{array}$ & $\begin{array}{c}0.988 * * \\
(0.685)\end{array}$ & $\begin{array}{l}1.000 * * \\
(0.013)\end{array}$ \\
\hline$r_{c} \pm S E$ & $\begin{array}{c}0.926 * * \\
(0.340)\end{array}$ & $\begin{array}{c}0.949 * * \\
(0.490)\end{array}$ & $\begin{array}{c}0.997 * * \\
(0.500)\end{array}$ & $\begin{array}{c}0.992 * * \\
(0.484)\end{array}$ & $\begin{array}{c}0.981 * * \\
(0.578)\end{array}$ & $\begin{array}{c}0.997 * * \\
(0.010)\end{array}$ \\
\hline$r_{p} \pm S E$ & $\begin{array}{c}0.448 * * \\
(0.039) \\
\end{array}$ & $\begin{array}{c}0.395 * * \\
(0.041)\end{array}$ & $\begin{array}{c}0.994 * * \\
(0.001)\end{array}$ & $\begin{array}{c}0.479 * * \\
(0.039)\end{array}$ & $\begin{array}{c}0.432 * * \\
(0.041)\end{array}$ & $\begin{array}{c}0.996 * * \\
(0.001)\end{array}$ \\
\hline
\end{tabular}

BW:birth weight, WW: weaning weight and ADG: average daily gain.

$\mathbf{r}_{\mathbf{c}}$ : maternal permanent environmental correlation. **: Highly significant $(\mathrm{P}<0.01)$

The direct genetic correlations $\left(\mathrm{r}_{\mathrm{g}}\right)$ between $\mathrm{BW}$ and each of WW and ADG were high close to unity for Barki lambs and were moderately high for Rahmani. The correlations between WW and ADG of Barki and Rahmani lambs were equal to unity (Table 4 ). Hence, selection for any of growth traits could cause genetic progress in the others. The current $r_{g}$ valuesshowed that there is high degree of direct genetic resemblance among the growth traits of Barki lambs in comparison with Rahmani. Jalil-Sarghaleet al. (2014) depicted moderate to high $r_{g}$ values of $0.72,0.52$ and 0.85 between $\mathrm{BW}$ and $\mathrm{WW}$, between $\mathrm{BW}$ and $\mathrm{ADG}$ and between WW and ADG of Baluchi lambs, respectively. Low to moderate $r_{g}$ values of $0.685,0.221$ and 0.687 between $\mathrm{BW}$ and $\mathrm{WW}$, between $\mathrm{BW}$ and $\mathrm{ADG}$ and between WW and ADG of White Boni Sheep, respectively were reported by AL-Bialet al. (2016).Significant $(P<0.01)$ and positive $r_{g}$ value of 1.00 between BW and WW of Bharat Merino sheep was found by Mallick et al. (2017). Jawasreh et al. (2018) depicted significant $(\mathrm{P}<0.01)$ and moderate positive $r_{g}$ values of $0.63,0.62$ and 0.67 between $B W$ and $\mathrm{WW}$, between $\mathrm{BW}$ and $\mathrm{ADG}$ and between $\mathrm{WW}$ and ADG of Awassi sheep, respectively. Sallamet al. (2019) obtained moderate to high $r_{g}$ values of 0.40 , 0.50 and 0.92 between $\mathrm{BW}$ and $\mathrm{WW}$, between $\mathrm{BW}$ and ADG and between WW and ADG of Barki lambs, respectively. The genetic correlation between two traits is properly due to the pleiotropic effects of genes on both traits. Therefore, genetic correlations are necessary for determination of the optimal breeding strategies required for genetic progress of the lambs' growth traits.

Maternal genetic correlations $\left(\mathrm{r}_{\mathrm{m}}\right)$ among growth traits of Barki lambs were high to extremely high close to unity (Table 4). Similarly, the $r_{m}$ values among growth traits of Rahmani were high to extremely high close to unity (Table 4). In view of the current $r_{m}$ values, there is high degree of maternal genetic resemblance among the growth trait of Rahmani lambs in comparison with Barki. Also, there is good evidence that maternal effects on WW and ADG are partly originating from the prenatal period. JalilSarghale et al. (2014) obtained moderate to high $\mathrm{r}_{\mathrm{m}}$ values of $0.67,0.54$ and 0.87 between $\mathrm{BW}$ and $\mathrm{WW}$, between BW and ADG and between WW and ADG of Baluchi lambs, respectively.

All maternal permanent environmental correlations $\left(r_{c}\right)$ among growth traits of both breeds were extremely high close to unity. The correlations indicated high degree of resemblance among the growth trait of both Barki and Rahmani lambs in their response to the permanent environmental effects. Jafari et al. (2012) found $r_{c}$ values of $0.44,0.31$ and 0.95 between $B W$ and $\mathrm{WW}$, between BW and ADG and between WW and ADG of Makuie lambs, respectively in Iran. Shokrollahi and Zandieh (2012) and Rashidi (2013) depicted low $r_{c}$ values of 0.35 and 0.21 between BW and WW of Kurdish sheep and Black sheep in Iran, respectively. Mokhtari et al. (2013) found $r_{c}$ values of $0.27,0.72$ and 0.64 between $\mathrm{BW}$ and $\mathrm{WW}$, between $\mathrm{BW}$ and $\mathrm{ADG}$ and between $\mathrm{WW}$ and $\mathrm{ADG}$ of Arman lambs in Iran, respectively.

The phenotypic correlations $\left(r_{p}\right)$ among the studied growth traits of Barki and Rahmani lambs ranged from 0.395 to 0.996 (Table 4). Jalil-Sarghale et al. (2014) depicted low to high $r_{p}$ values of 0.40 , 0.25 and 0.88 between $\mathrm{BW}$ and $\mathrm{WW}$, between $\mathrm{BW}$ and ADG and between WW and ADG of Baluchi lambs. AL-Bial et al. (2016) obtained low $r_{p}$ values of 0.331, 0.210 and 0.431 between $\mathrm{BW}$ and WW, between BW and ADG and between WW and ADG of White Boni Sheep, respectively. Mallick et al. (2017) found significant $(P<0.01)$ and moderate $r_{p}$ value of 0.37 
between BW and WW of Bharat Merino sheep. Jawasreh et al. $(2018)$ reported significant $(\mathrm{P}<0.01)$ moderate to high $r_{p}$ values of $0.48,0.48$ and 0.85 between $\mathrm{BW}$ and $\mathrm{WW}, \mathrm{BW}$ and $\mathrm{ADG}$ and between WW and ADG of Awassi sheep, respectively. Sallam et al. (2019) obtained low to high $r_{p}$ estimates of 0.28 , 0.12 and 0.88 between $\mathrm{BW}$ and $\mathrm{WW}$, between BW and ADG and between WW and ADG of Barki lambs, respectively. The phenotypic correlation could be attributed to genetic effects that are in common for the two traits, as well as environmental effects that affect both traits.

Table 5. Estimated breeding values (EBV) for the studied traits of Barki and Rahmani rams

\begin{tabular}{lcccccc}
\hline \multirow{2}{*}{ Trait } & \multicolumn{3}{c}{ Barki } & \multicolumn{3}{c}{ Rahmani } \\
\cline { 2 - 6 } & Min. & Max. & Range & Min. & Max. & Range \\
\cline { 2 - 6 } & -0.227 & 0.333 & 0.560 & -0.475 & 0.241 & 0.716 \\
BW (kg) & -1.666 & 2.444 & 4.110 & -3.995 & 2.983 & 6.978 \\
ADG (kg) & -11.60 & 17.00 & 28.60 & -27.21 & 20.57 & 47.78 \\
\hline
\end{tabular}

BW:birth weight, WW: weaning weight, ADG: average daily gain.

\section{Estimated breeding values (EBV):}

The estimated breeding value (EBV) is an estimate of the genetic potential of the animal expressed relative to the population average. The EBV for BW, WW and ADG of rams of both breeds are presented in Table (5). The ranges of EBV for all traits were higher for Rahmani rams than Barki. In view of the obtained EBV, there is good evidence that rams of both breeds had never been neither evaluated nor selected. Consequently, a considerable rate of genetic improvement in early growth traits of lamb could be achieved through selection of rams. Javed et al. (2013) reported that the EBV for BW and WW varied from -0.25 to 0.27 and from -0.99 to $1.30 \mathrm{~kg}$, respectively of Lohi lambs in Pakistan. Al-Samarai et al. (2015) indicated that the EBV ranged between 0.325 and 0.255 , between -1.142 and 1.284 and between -0.103 and $0.053 \mathrm{~kg}$ for BW, WW and ADG of Awasi rams, respectively. Yadav et al. (2018) found that the EBV varied between -0.07 and $0.18 \mathrm{~kg}$ and between 4.69 and $4.75 \mathrm{~kg}$ for BW and WW of Munjal rams, respectively.

\section{E- Genetic trends:}

Table (6) shows that regression coefficients (b) of estimated breeding values of rams on time were positive but insignificant for all traits of both breeds except for BW of Rahmani lambs that was significant $(\mathrm{P}<0.05)$. This might be attributed to lack of or ineffective selection of rams and to the changes occurred in the feeding regimes and management practices across the years. Hossein-Zadeh (2012) obtained significant $(\mathrm{P}<0.05)$ genetic trends of 1.63 and $69.2 \mathrm{~g} /$ year for BW and WW of Moghani sheep in Iran, respectively. Aguiree et al. (2016) reported slightly negative genetic trend of $-0.001 \mathrm{~kg} /$ year for BW and positive genetic trend of $0.04 \mathrm{~kg} /$ year for $\mathrm{WW}$ of Santa Ines sheep. Ahmadpanah et al. (2016) depicted significant $(\mathrm{P}<0.01)$ and positive direct genetic trends of $0.93 \mathrm{and} 43.74 \mathrm{~g} /$ year for BW and WW of IranianBlack sheep, respectively. Eteqadi et al. (2016) found significant $(\mathrm{P}<0.001)$ positive direct genetic trends of 0.51 and $5.56 \mathrm{~g} /$ year for BW and WW of sheep in Iran, respectively. Mallick et al. (2016) reported significant $(\mathrm{P}<0.01)$ positive genetic trends of $0.005 \mathrm{~kg} /$ year for $\mathrm{BW}$ and non-significant positive of $0.0008 \mathrm{~kg} /$ year for WW of Bharat Merino in India. Baneh and Ahmadpanah (2018) reported significant positive direct genetic trends of 2.34 and $46.20 \mathrm{~g} /$ year for BW and WW of Ghezel sheep in Turkey, respectively. On the contrary, Jawasreh et al. (2018) obtained significant $(\mathrm{P}<0.01)$ negative genetic trends of $0.0005,-0.006$, and $-0.0001 \mathrm{~kg} /$ year for $\mathrm{BW}$, WW and ADG of Awassi sheep in Jordan, respectively. Yadav et al. (2018) depicted negative genetic trends of -0.09 , and -0.25 and $-0.0001 \mathrm{~kg} /$ year for BW and WW of Munjal sheep, respectively. Sallam et al. (2019) obtained genetic trends of 2,180 and $2 \mathrm{~g} /$ year for BW, WW and ADG of Barki lambs, respectively.

Table 6. Regression coefficients $(b \pm)$ of estimated breeding values of rams on birth year for growth traits of Barki and Rahmani breeds.

\begin{tabular}{lcc}
\hline \multicolumn{1}{c}{ Trait } & Barki & Rahmani \\
\cline { 2 - 3 } & b \pm SE & b \pm SE \\
\hline Birth weight (kg) & $0.008^{\mathrm{NS}} \pm 0.008$ & $0.015^{*} \pm 0.007$ \\
Weaning weight (kg) & $0.057^{\mathrm{NS}} \pm 0.058$ & $0.143^{\mathrm{NS}} \pm 0.075$ \\
Average daily gain (g) & $0.396^{\mathrm{NS}} \pm 0.403$ & $0.978^{\mathrm{NS}} \pm 0.517$ \\
\hline
\end{tabular}

NS: Not significant $(\mathrm{P}>0.05)$, *: Significant $(\mathrm{P}<0.05)$

\section{CONCLUSIONS}

The low direct genetic variations in $\mathrm{WW}$ and ADG of Barki and Rahmani lambs indicated that improvement of these traits by selection would result in slow genetic changes. The maternal effects were considerable portion of variation in early growth traits of lambs of both breeds. The high and positive genetic correlations among lambs' growth traits indicated that improvement of any trait by selection would cause positive changes in the others. The wide range of rams breeding values for $\mathrm{BW}, \mathrm{WW}$ and $\mathrm{ADG}$ 
in both breeds was probably due to the absence of selection or planned matings since the rams had never been neither evaluated nor selected. Consequently, a considerable rate of genetic improvement in lamb growth traits could be obtained by selection of rams based on their breeding values. The results in general showed the need for designing an effective selection programme to improve growth traits of lambs in both breeds.

\section{ACKNOWLEDGMEN}

The authors are grateful to Mr. Ahmed Moustafa Mahmoud, the former specialist of sheep and goats at the Experimental Station for making the data available.

\section{REFERENCES}

Abbas, S.F., M. Abdl Allah, F.M. Allam and A.A. Abul-Ella, 2010. Growth performance of Rahmani and Chios lambs weaned at different ages. Aust. J. Basic and Appl. Sci., 4: 1583-1589.

Aguirre, E.L., E.C. Mattos, J.P. Eler, A.D. Barreto Neto and J.B. Ferraz, 2016. Estimation of genetic parameters and genetic changes for growth characteristics of Santa Ines sheep. Genet. Mole. Res. (gmr), 15: 1-12.

Ahmadpanah, J., H. Baneh and C. Kohnepoushi, 2016. Direct and maternal genetic trend estimates for body weight traits of Iran-Black Sheep using multivariate animal models. Songklanakarin J. Sci. Technol., 38: 305-310.

Akhtar, M.,K. Javed and M. Abdullah, 2014. Single trait analysis for preweaninggrowth traits of Buchi sheep in Pakistan. The J. Anim. Plant Sci., 24: 693-699.

Aksoy, Y., Z. Ulutas, U. ŞEN, E. ŞİRİN and A. ŞAHIN 2016).Estimates of genetic parameters for different body weights and muscle and fat depths of Karayaka lambs. Turk .J. Vet. Anim. Sci., 40: 13-20.

AL-Bial, A., S. Alazazie , A. Shami and A. Aldoss, 2016. Genetic analysis of growth traits in White Boni sheep under the Central Highlands Region of Yemen. J. basic appl. Res., 2: 408-413.

Al-Samarai, F. R., F. A. Mohammed, N. N. AlAnbari, H. F. Al-Zaydi, Y.K. Abdulrahman, 2015. BLUP Values of Birth to Weaning Growth Traits of Awassi Lambs in Iraq. Russ. J. Biolog. Res., 5: 116-123.

Baneh, H. and J. Ahmadpanah, 2018. Genetic evaluation of body weight traits in Iranian native Ghezel sheep. Genetika, 50: 275-284.

Bayeriyar, M. and F. Hadi, 2016. Genetic parameters for live weight and reproductive traits in Moghani Sheep. Int. J. Adv. Biotechnol. Res., (IJBR), 7:829-834.

Eteqadi, B., N. Ghavi Hossein-Zadeh and A.A. Shadparvar, 2016. Estimation of genetic and phenotypic trends for body weight traits of sheep in Guilan province of Iran. J. Livest. Sci. Technol., 4: 57-62.

Gad, S.M.A. and S.I. El-Wakil, 2013. Estimates of genetic parameters of early growth traits of Barki sheep in Egypt. J. Anim. Poult. Prod., Mansura Univ., 4: 783-789.

Hossein-Zadeh, N.G., 2012. Bayesian estimates of genetic changes for body weight traits of Moghani sheep using Gibbs sampling. Trop. Anim. health Prod., 44: 531-536.

Jafari, S., G. Manafiazar, R. Darvishzadeh, S. Razzagzadeh and M. Farhadianl, 2012. Genetic analysis of growth traits in Iranian Makuie sheep breed. Ital. J. Anim Sci., 8: 98-102.

Jalil-Sarghale, A., M. Kholghi, M. Moradi Shahrebabak, H. Moradi Shahrebabak, H. Mohammadi and R. Abdollahi-Arpanahi (2014). Model comparisons and genetic parameter estimates of growth traits in Baluchi sheep. Slovak J. Anim. Sci., 47: 12-18.

Jannoune, A., I. Boujenane, M. Falaki and L. Derqaoui, 2015. Genetic analysis of live weight of Sardi sheep using random regression and multi-trait animal models. Small Rum. Res., 130: $1-7$.

Javed, K., A. Iram, M. Abdullah, M.A. Sattar and R.M. Akthar, 2013. Genetic trends for some productive traits of Lohi sheep in Pakistan. Pak. J. Anim. Sci., 65: 492-495.

Jawasreh, K., Z. B. Ismail, F. Iya, V.J. CastañedaBustos and M. Valencia-Posadas, 2018. Genetic parameter estimation for pre-weaning growth traits in Jordan Awassi sheep. Vet. World, 11: 254-258.

Mallick, P. K., R. Pourouchottamane, S Rajapandi, S.M.K. Thirumaran, R Venkataraman, G.Nagarajan, G. Murali and A.S. Rajendiran, 2017. Influence of genetic and non genetic factors on growth traits of Bharat Merino sheep in subtemperate climate of Kodai hills of Tamil Nadu, India. Indian J. Anim. Res., 51: 365-370.

Mallick, P. K., S. M. K. Thirumaran, R. Pourouchottamane, S. Rajapandi, R. Venkataramanan, G. Nagarajan, G. Murali and A.S. Rajendiran, 2016. Genetic trend for growth and wool performance in a closed flock of Bharat Merino sheep at sub temperate region of Kodai hills, Tamil Nadu. Vet. World, 9: 276-280.

Marufa, E., M. Taye, G. Abebe, A. Tera and A. Jimma, 2017. Effect of non-genetic factors on reproductive and growth performanceof Abera sheep under community based breeding program in SNNPRS Ethiopia. J. Adv. Dairy Res., 5: 196202.

Meyer, K., 2006. WOMBAT - Digging deep for quantitative genetic analyses by restricted maximum likelihood. Proc. $8^{\text {th }}$ World Congress of Genetics Applied for Livestock. Production, Communication No. 27: 14.17.

Mohammadi, K., R. Abdollahi-Arpanahi, F. Amraei and E.M. Mohamadi, 2015. Genetic parameter 
estimates for growth and reproductive traits in Lori sheep. Small Rum. Res., 131: 35-42.

Mohammadi, H., M. Moradi-Shahrebabak, H.Moradi-Shahrebabak, A. Bahrami andM. Dorostkar, 2013. Model comparisons and genetic parameter estimates of growth and the Kleiber ratio in Shal sheep. Archiv Tierz., 56: 264-275.

Mokhtari, M.S., M. Moradi Sharebabak., H. Moradi Sharebabak and M. Sadeghi, 2013. Estimation of (co) variance components and genetic parameters for growth traits in Arman sheep. J. Livest .Sci. Technol., 1: 38-47.

Mostafa, L.F., R. Hedayatollah, A. Saeed, M. Kourosh and M. Khalil, 2011. Genetic trends estimation for some of the growth traits in Arman sheep. J. Anim. Vet. Adv., 10: 1801-1803.

Rahimi, S.M., A.R. Rafat and S. Jafari, 2014. Effects of environmental factors on growth traits in Makuie sheep. Biotechnol. Anim. Husb., 30: 185192.

Rashidi, A., 2013. Genetic parameter estimates of body weight traits in Iran-Black sheep. J. Livest. Sci. Technol., 1: 54-60.

Roshanfekr, H. (2014). Estimation of genetic parameters for Kleiber ratio and trends for weight and weaning in Arabi sheep. Int. J. Adv. Biol. Biom. Res., 31: 23-36.

Sallam, A.M., A.H. Ibrahim and S.M. Alsheikh, 2019. Estimation of genetic parameters and variance components of pre-weaning growth traits in Barki lambs. Small Rum. Res., 173: 94-100.
SAS, 2008. Statistical Analysis System user's Guide, (Release 9.2). SAS Institute Inc., Cary, North Carolina, USA.

Selvaggi, M., F. Pinto, A.R. Pesce Delfino, A. Vicenti and C. Dario, 2011. Phenotypic and genetic parameters of pre-weaning growth traits in Gentile di Puglia lambs. World Acad. Sci. Eng. Technol., 5: 377-379.

Shokrollahi, B. and M. Zandieh, 2012. Estimation of genetic parameters for body weights of Kurdish sheep in various ages using multivariate animal models. Afric. J. Biotechnol., 11: 2119-2123.

Taghi, B. N. M., A. Asefi, M. Karami and J. Fayazi, 2016. Bayesian estimation of genetic parameters of growth traits in zanadi sheep. Basrah J. Vet. Res., 15: 236-253.

Tohidi R., A. Javanm and V. Shamsabadi, 2016. Analysis of the non-genetic factors affecting the growth traits of Balouchi sheep. J. Bio. Env. Sci., 8: 67-73.

Yadav, U., Z.S. Malik, D.S. Dalal, S.P. Dahiya and C.S. Patil, 2018. Estimation of breeding values and genetic trend of production traits in Munjal Sheep. Int. J. Livest. Res., 8: 135-141.

\title{
التحليل الوراثي لصفات التمو قبل الفطام للحملان البرقى والرحمانى
}

\author{
محمد حسن حمود ، محمد محمود سالم \\ قسم الإتتاج العيوانسى والسككي، كلية الزراعة، جامعة الإسكندرية

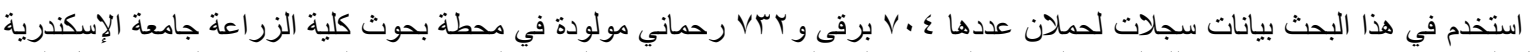

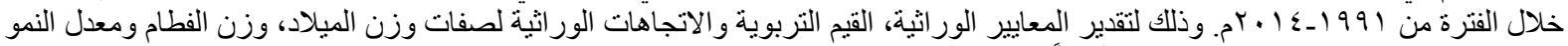

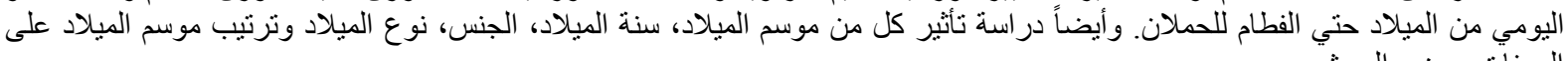

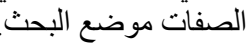

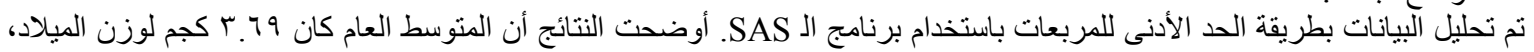

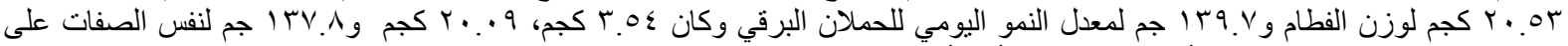

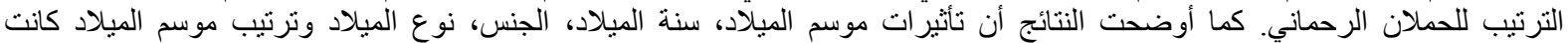

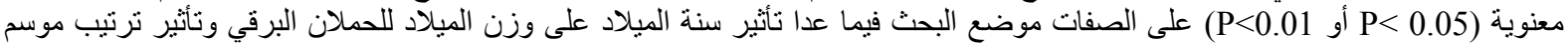

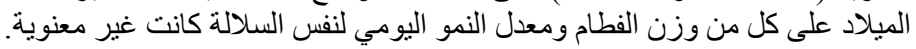

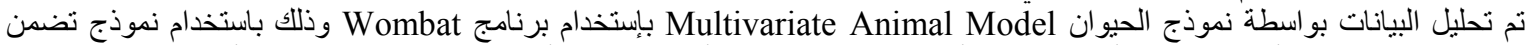

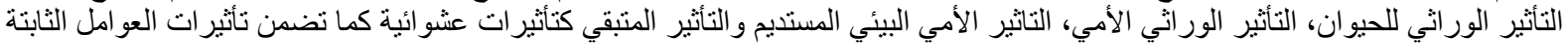

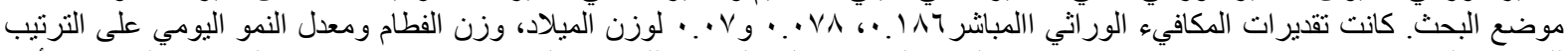

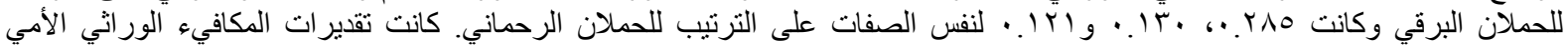

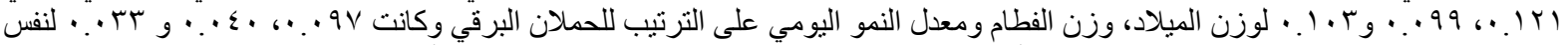

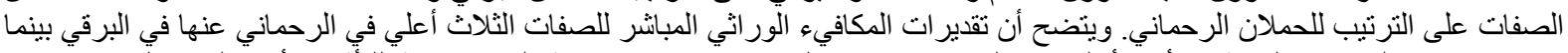

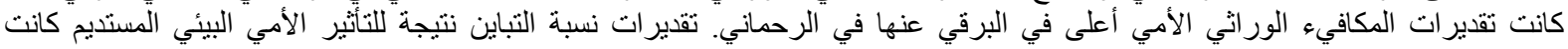

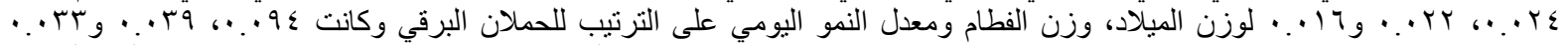

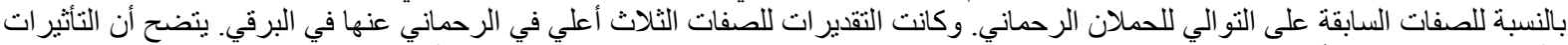

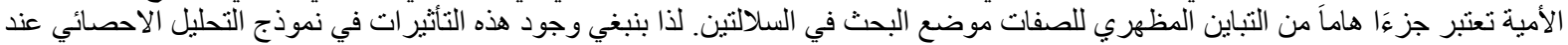

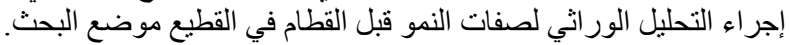

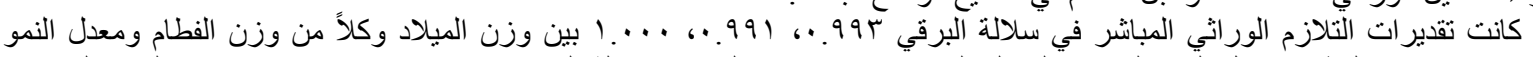

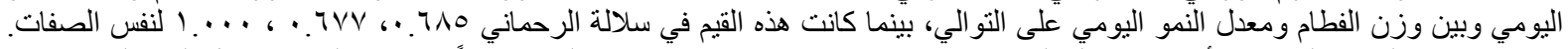

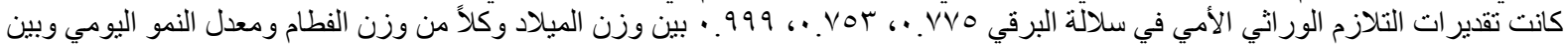




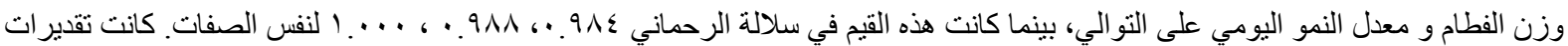

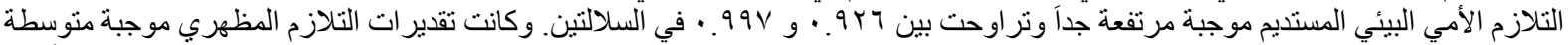

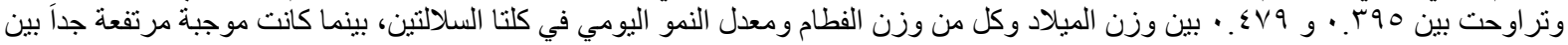

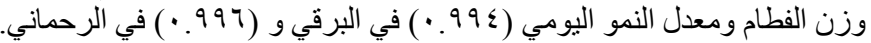

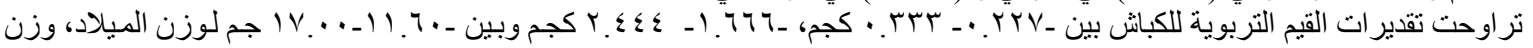

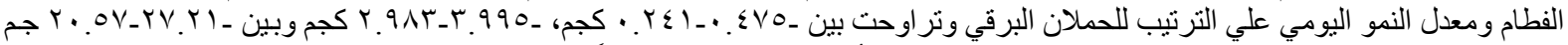

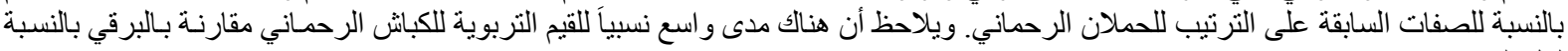
لكل الصفات.

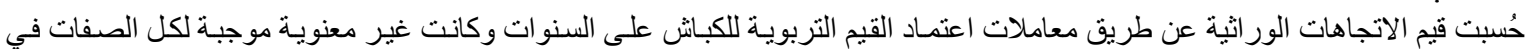

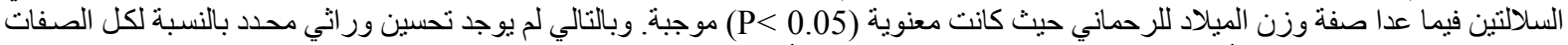

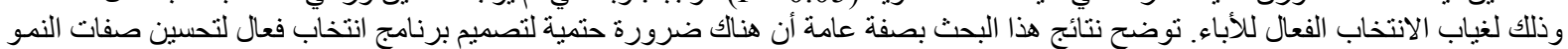

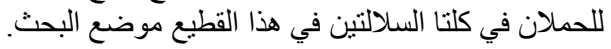

